
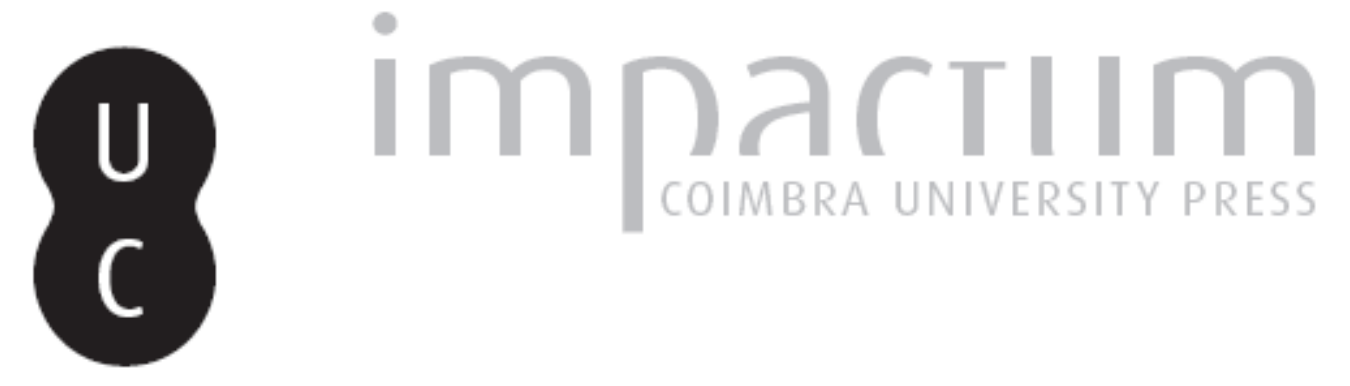

\title{
Epigrafia monetária meridional
}

\section{Autor(es): $\quad$ Faria, António Marques de}

Publicado por: Imprensa da Universidade de Coimbra

URL persistente:

URI:http://hdl.handle.net/10316.2/45524

DOI:

DOI:https://dx.doi.org/10.14195/1647-8657_30_2

Accessed : $\quad$ 26-Apr-2023 13:30:53

A navegação consulta e descarregamento dos títulos inseridos nas Bibliotecas Digitais UC Digitalis, UC Pombalina e UC Impactum, pressupõem a aceitação plena e sem reservas dos Termos e Condições de Uso destas Bibliotecas Digitais, disponíveis em https://digitalis.uc.pt/pt-pt/termos.

Conforme exposto nos referidos Termos e Condições de Uso, o descarregamento de títulos de acesso restrito requer uma licença válida de autorização devendo o utilizador aceder ao(s) documento(s) a partir de um endereço de IP da instituição detentora da supramencionada licença.

Ao utilizador é apenas permitido o descarregamento para uso pessoal, pelo que o emprego do(s) título(s) descarregado(s) para outro fim, designadamente comercial, carece de autorização do respetivo autor ou editor da obra.

Na medida em que todas as obras da UC Digitalis se encontram protegidas pelo Código do Direito de Autor e Direitos Conexos e demais legislação aplicável, toda a cópia, parcial ou total, deste documento, nos casos em que é legalmente admitida, deverá conter ou fazer-se acompanhar por este aviso.

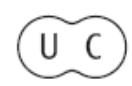


FACULDADE DE LETRAS

INSTITUTO DE ARQUEOLOGIA

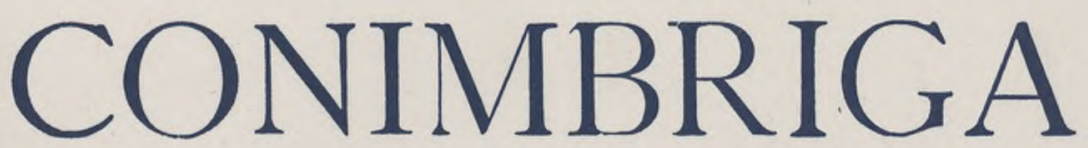

VOLUME XXX

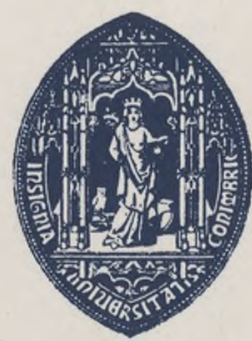

UNIVERSIDADE DE COIMBRA 


\section{ANTÓNIO MARQUes de Faria}

Técnico do Instituto Português do Património Arquitectónico e Arqueológico

EPIGRAFIA MONETÁRIA MERIDIONAL

"Conimbriga" XXX (1991), p. 13-21

Resumo: Uma vez removidas as dificuldades que se colocavam à total interpre-

tação das legendas monetárias em escrita meridional, quisemos, neste trabalho, fornecer uma leitura de todas as inscrições em questão. Para além de novas interpretações avançadas para algumas legendas toponímicas, são tecidos alguns comentários a respeito da filiação étnica e linguística de diversos antropónimos reproduzidos nas emissões monetárias referidas.

Summary: Considering the fact that there are no serious problems in the reading of most of the signs belonging to southern Iberian script, we think it is time to present a complete list of words - personal and place names included in coins that made use of that kind of script. A few proposals are made about the reading of some place names and also about the origin of personal names that have been almost ignored in other works. 
(Página deixada propositadamente em branco) 


\section{EPIGRAFIA MONETÁRIA MERIDIONAL}

Não tem havido grande unanimidade na identificação das cecas que, durante os dois ou três últimos séculos a. C., utilizaram este sistema de escrita (Untermann, 1975, p. 74-76; De Hoz, 1980, p. 303-304). Queremos, com o presente texto, dar o nosso contributo para a discussão deste tema, que continua à espera de um esclarecimento definitivo. Para tanto, tomaremos como ponto de partida o já citado trabalho de Untermann; os códigos alfanuméricos que se seguem às legendas monetárias remetem naturalmente para aquela obra.

Os vocábulos a negro constituem as transcrições de nomes em escrita meridional, de acordo com os valores de cada um dos signos expostos na fig. 1 (Faria, 1990/91, com bibliografia anterior).

iKale(n)sKen (A. 95): Partindo do princípio de que $S 20$ também serviu para representar, nas inscrições monetárias meridionais, a consoante $k / g$ (Correa, 1983 b, p. 109 e 111), é possível que os "iKale(n)sKen" correspondam aos 'IyÀ,r|T 8ç de Estrabão (Geogr. III, 4, 19) (Gómez-Moreno, 1949, p. 185); se assim for, e caso o étnico iKalesKen tenha derivado do nome de uma cidade, este poderá ter sido */g///e/a.

urKesKen (A. 96): Para além das observações de De Hoz (1980, p. 313), nada parece haver a acrescentar ao que sobre esta ceca escreveu Untermann (1975, p. 324-325).

KaSTilo (A. 97): A legenda toponímica é a única palavra que figura inscrita em caracteres meridionais na maior parte das emissões. Apenas numa emissão que utiliza a escrita latina em todos os seus letreiros, encontramos o topónimo abreviado sob a forma CAST (A. 97-5.). Existem outras emissões sem legenda toponímica que, pelo estilo, têm sido atribuídas à mesma ceca. Cada uma delas apresenta, em caracteres 
latinos, nomes de magistrados-dois nos semisses e três nos asses-que se identificam, na maior parte dos casos, por praenomina latinos acompanhados dos respectivos patronímicos abreviados, quase sempre de origem ibérica, $u$. g., Bal(ce...), Qul(es...) eise (er...). E o caso da emissão Vives LXXI, nQ 14, que apresenta nos anversos L. QVL. F e Q. ISC. F, ostentando nos reversos as iniciais M. C. F. Pertencendo esta emissão aos finais do século II a. C. ou aos princípios do século seguinte (Faria, 1987, p. 26), é natural que as emissões Vives LXXI, n. ${ }^{\text {s }} 6$ e 8 , estilísticamente afins daquela, apresentem uma cronologia semelhante. Anteriores a qualquer delas deverão ser as emissões Vives LXX, nQ 13 e LXXI, nQ 1, se, como sugere Villaronga (1979, p. 231), o magistrado Q. Isc. /(Vives LXXI, $\mathrm{n}^{\mathrm{Q}}$ 14) for filho deM Isc. (Vives LXXI, $\mathrm{n}^{\mathrm{Q}}$ 1), talvez o mesmo Iscer presente em Vives LXX, nQ 13.

ilTiKira (A.98): Esta leitura da legenda A.98-1.2, que agora apresentamos, já havia sido, a par de outras, sugerida por De Hoz (1980, p. 305). Por razões que desconhecemos, $S l b$, grafema que encerra aquele letreiro, ficou por transliterar, se bem que a sua leitura como $a$ não tenha sido, no mesmo trabalho, totalmente descartada (De Hoz, 1980, p. 304, cuadro 2, GM 1 e GM14). Tendo em conta que Obulco é a tradução latina de iBoIKa (Untermann, 1975, p. 336; v., no entanto, Correa, 1983 b, p. 110), não é impossível acreditar que ilTiKira tenha dado origem a Huero, NL documentado em lingotes de chumbo romanos (Domergue, 1966, p. 59, nota 69 e p. 62; Domergue, 1987, p. 400-404).

UTuRiR/ilTuKiiKi (A.99): Devendo evitar-se a interpretação de qualquer inscrição com base na mistura de signos pertencentes a distintos sistemas de escrita (De Hoz, 1980, p. 304), apenas duas leituras se nos afiguram prováveis para a legenda A.99.-2.5:

a) ilTuRiR: KeSTin, se atribuirmos os caracteres ao sistema levantino; é também esta a leitura de Untermann (1975, p. 75), apesar de os incluir no semi-silabário meridional.

b) ilTuKiiKi: KeSen, se considerarmos que a legenda é composta por signos meridionais. A confirmar-se a inclusão destes signos no signário meridional, a legenda ilTuKiiKi poderia talvez segmentar-se da seguinte maneira: ilTuKi-iK(i), ou seja, o nome ilTuKi seguido do sufixo -iKi (Untermann, 1985-1986, p. 40). Para além de Ilici, poderá aventar-se como paralelo para este possível topónimo o NL Illuda, veiculado por Tito Livio (XXXV, 7, 7). 
Convém ter em atenção que a opção levantina tem contra si a localização da ceca, bem no coração da área de distribuição da escrita meridional. Porém, se os caracteres forem mesmo levantinos, o nome Iliberi, versão latina do topónimo, reproduzido em emissões atribuíveis àquela mesma ceca (Vives y Escudero, 1924-1926, lám. LXXIII, n.os 9 e 10), poderá ser explicado através da comparação com as legendas toponímicas das moedas de Saetabi:SaiTi (ibérico) e Saetabi (latim). Sendo aqui notória a síncope de /ab/, torna-se possível conjecturar que semelhante fenómeno tenha ocorrido na ceca em análise; deste modo, a legenda A.99.-2.5 deverá ser lida como ilTu(be)Ri-R: KeSTin. Se tal interpretação estiver correda, será difícil não relacionar o segundo termo com o NP Icstnis( CILII, 1585) (Lafon, 1963, p.402). A vibrante que sucede ao topónimo deverá constituir um morfema já isolado, surgindo normalmente posposto a NNP e, em menor grau, a NNL, entre os quais se conta SaiT(ab)i-R (Ripollès, 1991, p. 70 e p. 73, nota 2). Figurando sob as grafias -(a)r/-(a)R, (Untermann, 1975, p. 80; Untermann, 1976, p. 220; Tovar, 1979, p. 482-483; De Hoz, 1983, p. 389-390), este sufixo parece ser marca de genitivo, no que se confunde com -(e)n, outra partícula com a qual aparece, por vezes, associado (Michelena, 1976, p. 353-361).

iBolKa/Obn/co (A. 100): Recordemos os nomes, em escrita meridional, dos magistrados presentes na numária desta ceca (De Hoz, 1980, p. 314; Arévalo González, 1989, p. 143-147):
A. 100-2.: SiBiBolai/urKail
A. 100-3.: HTireur/KaRsuriTu
A.100-4.: TuiTuBolai /isKeraTin
A.100-5.: isKeraTin/TuiTuBolai
A.100-6.: TuiT uiBoren/ãnT uaKoi
A. 100-7.: TuiTuiBoren/annTuaKoi
A.100-8.: urKailBi/neselTuKo
A. 100-9.: neselTuKo/urKailBi
A.100-10.: BeKoeKi/BoTilKoS
A.100-11.: BoTilKoS/BeKoeKi
A.100-12.: ilTiraTin/Kolon
A.100-13.: siKaai/oTaKiiS

ilTireur, ilTiraTin, isKeraTin, neselTuKo e KaRsuriTu são NNP ibéricos. Apenas os dois últimos merecem, dentro deste grupo, um curto aditamento aos comentários de Untermann (1975, p. 337-338): ambos são 
compostos por mais de dois elementos nominais: nes-ilTu-Ko (justificándose -elTu- por assimilação vocálica) e KaR-sur-i-Tu.

Todos os outros poderão pertencer à onomástica pessoal turde tana. A estes deve-se acrescentar o NP abreviado Conipr., que figura em caracteres latinos numa emissão da mesma ceca (A. 100-15.). Se não forem apenas fonéticas as semelhanças entre este antropònimo e os NNP KaniBeron e KoBeroi, citados no chumbo de Mogente (Faria, 1990/91, p. 77, 81), tanto *Conipron como *Coniproi poderão constituir o nome completo do magistrado em questão. Do mesmo modo, qualquer destas terminações poderá ser aplicada quer a Conip., nome representado numa emissão de Onuba (Collantes Pérez-Ardá, 1987-1989, p. 94), quer a Cantnip., constante de uma emissão de *BeuiBum (A. 103) (Faria, 1989, p. 85).

Abra (A. 101): Esta ceca apresenta apenas um par de magistrados, ambos de origem turdetana:

A. 101-2.: ueKoeKi/ãnKioniS

\section{A.101-3.: ãnKioniS/ueKoeKi}

O NP ueKoeKi está também presente numa emissão de iBolKa/Obulco (A.100-10., -11.). Nesta última ceca, porém, houve o recurso à bilabial oral sonora para representar a semivogal inicial (Corominas, 1976, p. 124; Tovar, 1979, p. 474-475). Esta variação gráfica infere-se igualmente da presença, no chumbo greco-etrusco de Pech Maho, datado da primeira metade do século V a. G, do NP *Ncmapuaç (Lejeune et alii, 1988, p. 53); aqui, em vez da semivogal, esperar-se-ia a utilização da bilabial, que encontramos, por exemplo, em *naBaRsosin (Siles, 1985, p. 268, nQ 1164) ou nos diversos NNP ibéricos que contêm o elemento -BaS (Untermann, 1987, p. 299, $\left.\mathrm{n}^{\mathrm{s}} 21\right)$.

Ceca anónima (A. 102): nesta ceca, apenas podemos salientar a presença de dois magistrados de nomes tipicamente turdetanos, Ka(a)nKinai e TeKiailKoS, que se distribuem por duas legendas de reverso (Arévalo González, 1990, p. 7-10):

\section{A. 102-1.: KanKinai/TeKiailKoS}

\section{A. 102-2.: KaanKinai/TeKiailKoS}

Repare-se que ambas as terminações,-ai e -ilKoS, estão, por mais de uma vez, consignadas na onomástica obulconense.

*BeuiBum (A. 103): sobre esta ceca pouco mais temos a dizer em relação ao que escrevemos em anteriores trabalhos (Faria, 1989, p. 71-99; 
Faria, 1992, p. 39-48 ). Apenas terá ficado por sublinhar a disparidade fonética que existe entre a nossa mais recente leitura da legenda toponímica e o potamónimo *KaÀÀiJtxyuç;, veiculado por Ptolemeu (Geogr., II, 5,2). Bem mais próximo deste encontra-se -auiPon, leitura que dela apresentou Correa (1982, p. 73), baseado nas interpretações que ele e outros linguistas têm dado a diversos grafemas pertencentes ao signário do Sudoeste. Porém, cremos que se mantêm as objecções que colocámos à integração dos grafemas de *BeuiBum naquele signário :

a) As moedas foram emitidas presumivelmente a partir da 2- metade do século II a. C, tendo a escrita do Sudoeste desaparecido nos finais do século V a. C. (Correa, 1989, p. 286).

b) A ceca situa-se numa área onde, até hoje, não foram encontrados quaisquer exemplos daquela epigrafia funerária, que conta apenas com testemunhos conhecidos a sul de Beja e a leste de Badajoz (Beirão, 1990, p. 108).

c) Os grafemas de sequência vocálica fixa - decerto a principal característica dos textos em escrita do Sudoeste - encontram-se totalmente ausentes da legenda monetária em questão (Correa, 1985-1986, p. 277).

d) A sequência fonética -il-, presente nos nomes de dois magistrados de *BeuiBum, parece ser completamente alheia à língua transmitida nas lápides do Sudoeste (Correa, 1983 a, p. 407; Correa, 1985, p. 384 e nota 16). Este argumento só tem validade se partirmos do princípio de que os nomes dos magistrados pertencem à língua falada pelo povo que criou não só o topónimo em questão mas também o sistema de escrita que permitiu a respectiva representação gráfica.

A serem correctos os argumentos que apresentámos no sentido de atribuir os signos constantes daquela legenda ao semi-silabário meridional, a leitura que dela fizemos só poderá divergir da verdadeira interpretação na valorização do grafema que a encerra, se este representar a alveolar nasal.

\section{BIBLIOGRAFIA}

Arévalo González, A., 1989, Las monedas bilingües de Obulco, "Gaceta Numismática", 94-95, p. 143-147.

ARÉvalo GonzÁlez, A., 1990, Consideraciones sobre unas monedas de taller incierto, "Gaceta Numismática", 99, p. 7-10.

BeIrão, C. de M., 1990, Epigrafia da I Idade do Ferro do Sudoeste da Península

Ibérica. Novos dados arqueológicos, "Estudos Orientais", 1, p. 107-118.

Conimbriga, 30 (1991), 13-21 
Collantes Pérez-ARdÁ, E., 1987-1989, Conjeturas sobre metrologia ibérica, "Numisma", 204-221, p. 29-107.

Corominas, J, 1976, Elementos prelatinos en las lenguas romances hispánicas, “Actas del I Coloquio sobre Lenguas y Culturas Prerromanas de la Península Ibérica (Salamanca, 27-31 mayo 1974)”, Salamanca, Universidad, p. 87-164.

Correa, J. A., 1982, Singularidad del letrero indigena de las monedas de Salada (A. 103), "Numisma", 177-179, p. 69-74.

Correa, J. A., 1983 a, Escritura y lengua prerromanas en el sur de la Península Ibérica, "Unidad y Pluralidad del Mundo Antiguo. Actas del VI Congreso Español de Estudios Clásicos (Sevilla, 6-11 de abril de 1981)”, I, Madrid, Gredos, p. 397-411.

Correa, J. A., 1983 b, Ibérico: Cás(i)lo, Ibolc(a), latín: Castulo, Obulco, "Habis", 14, p. 107-113.

Correa, J. A., 1985, Consideraciones sobre las inscripciones tartesias, "Actas del III Coloquio sobre Lenguas y Culturas Paleohispánicas (Lisboa, 5-8 noviembre 1980)", Salamanca, Universidad, p. 377-395.

Correa, J. A., 1985-1986, El signarlo tartesio, "Veleia", 2-3, p. 275-284.

Correa, J. A., 1989, El origen de la escriturapaleohispánica, "Estudios sobre Urso Colonia Iulia Genetiva”, Sevilla, Alfar, p. 281-302.

Domergue, C., 1966, Les lingots de plomb romains du Musée Archéologique de Carthagène et du Musée N aval de Madrid, "Archivo Español de Arqueología", 39, p. 41-73.

Domergue, C., 1987, Catalogue des mines et des fonderies antiques de la Péninsule Ibérique, II, Madrid, Diffusion De Boccard.

FARIA, A. M. de, 1987, Moedas de chumbo, da época romana, cunhadas no actual territòrio português, "Numismática", 47, p. 24-28.

Faria, A. M. de, 1989, A numária de *Cantnipo, “Conimbriga”, 28, p. 71-99.

FARIA, A. M. de, 1990/91, Antropónimos em inscrições hispânicas meridionais, "Portugalia", nova série, 11-12, p. 73-88.

Faria, A. M. de, 1992, Ainda sobre o nome pré-romano de Alcácer do Sal, "Vipasca", 1, p. 39-48.

Gómez-Moreno, M., 1949, Misceláneas. Historia-Arte-Arqueología, Madrid, Consejo Superior de Investigaciones Científicas.

Hoz, J., de 1980, Crónica de lingüística y epigrafía prerromanas de la Península Ibérica: 1979, "Zephyrus", 30-31, p. 299-323.

Hoz, J., de 1983, Las lenguas y la epigrafia prerromanas de la Península Ibérica, "Unidad y Pluralidad del Mundo Antiguo. Actas del VI Congreso Español de Estudios Clásicos (Sevilla, 6-11 de abril de 1981)", I, Madrid, Gredos, p. 351-396. 
LAFon, R., 1963, Noms anciens de personnes et de lieux du Sud de l'Espagne d'après les inscriptions, "Atti e Memorie del VII Congresso Intemazionale di Scienze Onomastiche (Firenze, 1961)”, III, Firenze, p. 401-406.

LeJeune, M. et alii, 1988, Étrusque et ionien archaïques sur un plomb de Pech Maho (Aude), "Revue Archéologique de Narbonnaise", 21, p. 19-59.

Michelena, L., 1976, Ibérico -en, "Actas del I Coloquio sobre Lenguas y Culturas Prerromanas de la Península Ibérica (Salamanca, 27-31 mayo 1974)", Salamanca: Universidad, p. 353-361.

Ripollès, P. P., 1991, Una emisión de Saitabi inédita, "Saguntum", 24, Valência, p. 69-73.

SILES, J., 1985, Léxico de inscripciones ibéricas, Madrid, Ministerio de Cultura.

Tovar, A, 1979, Notas lingüísticas sobre monedas ibéricas, "Actas del II Coloquio sobre Lenguas y Culturas Prerromanas de la Península Ibérica (Tübingen, 1719 junio 1976)", Salamanca, Universidad, p. 473-489.

UntermanN, J., 1975, Monumenta Linguarum Hispanicarum, I., Wiesbaden, Dr.Ludwig Reichert Verlag.

Untermann, J., 1976, Las leyendas monetales, “Actas del I Coloquio sobre Lenguas y Culturas Prerromanas de la Península Ibérica (Salamanca, 27-31 mayo 1974)", Salamanca, Universidad, p. 213-225.

Untermann, J., 1985-1986, La gramática de los plomos ibéricos, "Veleia", 2-3, p. $35-56$.

Villaronga, L., 1979, Numismática antigua de Hispania, Barcelona, Cymys.

Vives y Escudero, A., 1924-1926, La moneda hispánica, Madrid, Real Academia de la Historia, 4 vols. 


\begin{tabular}{|c|c|c|c|c|c|c|c|c|c|c|c|c|c|c|}
\hline & - & $\mathrm{a}$ & $b$ & & & - & $\mathrm{a}$ & $b$ & & & - & $\mathrm{a}$ & $b$ & \\
\hline 1 & 4 & $\not$ & $\lambda$ & $a$ & 11 & V & $y$ & & $\mathrm{~m}$ ? & 21 & 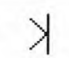 & & ) & $\mathrm{Ke}$ \\
\hline 2 & 0 & $\otimes$ & $\otimes$ & $e$ & 12 & 寿 & $\mathscr{K}$ & & $s$ & 22 & $\phi$ & Q & & $\mathrm{Ki}$ \\
\hline 3 & 4 & & & $e$ & 13 & $M$ & & & $S$ & 23 & & & & $\mathrm{Ki}$ \\
\hline 4 & 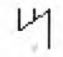 & & & $\mathrm{i}$ & 14 & & & & $\mathrm{Ba}$ & 24 & $\infty$ & $D$ & 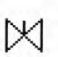 & $\mathrm{Ko}$ \\
\hline 5 & $\neq$ & $\not{K}$ & & 0 & 15 & $y$ & $\forall$ & $\exists$ & $\mathrm{Be}$ & 25 & 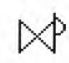 & & & $\mathrm{Ku}$ \\
\hline 6 & 4 & & & $u$ & 16 & $<$ & & & $\mathrm{Be}$ & 26 & & & & $\mathrm{Ta}$ \\
\hline 7 & & & & 1 & 17 & & & & $\mathrm{Bi}$ & 27 & $E$ & & & $\mathrm{Te}$ \\
\hline 8 & 9 & 0 & $y$ & $\mathrm{r}$ & 18 & W & $\left|\begin{array}{l}1 \\
1\end{array}\right|$ & & Bo & 28 & & & & $\mathrm{Ti}$ \\
\hline 9 & $\gamma^{\prime}$ & & & $\mathrm{R}$ & 19 & & & & $\mathrm{Bu}$ & 29 & $\bigsqcup$ & & & To \\
\hline 10 & 丩 & & & $\mathrm{n}$ & 20 & & & & $\mathrm{Ka}$ & 30 & & 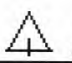 & & $\mathrm{Tu}$ \\
\hline
\end{tabular}

FIG. 1. Signário meridional 